\title{
Putting innovation to the test
}

\author{
Fiona Godlee editor in chief
}

The BMJ

NHS staff and patients face the prospect of continued austerity after the chancellor fell short of meeting NHS England's request for at least $£ 4$ bn to meet growing demand (doi:10.1136/bmj. j5422). How should we respond? (Watch The BMJ's Facebook Live event at http://bit.ly/2AtfCGS for health policy experts' response to the autumn budget.)

Tight budgets can, of course, stimulate innovation, as Caroline White found when investigating the effect of cuts to England's sexual health services (doi:10.1136/bmj.j5395). Local authorities have responded innovatively, absorbing rising demand within fixed budgets through efficiencies and new ways of working, says White's report (which has an accompanying interactive map showing county by county changes in sexual health service budgets). Moving some services online, integrating others, and changing payment structures have secured clinical provision, despite diminishing resources.

But innovation has its limits. White quotes David Buck of the health think tank the King's Fund. "The fat has already gone," he says. "We are about at the limit now, and in some places have gone beyond it." This is especially true as needs become more complex. Syphilis is on the rise, White explains, and "chemsex" and other social changes bring new challenges. Restrictions and closures are already happening below the radar, and prevention and promotion are likely to be particularly badly hit. Some losses are hidden within the data. Chlamydia diagnoses have fallen, for example, but perhaps because fewer tests are being done. "It's a mixed picture, and not all bad," says Buck, "but no one was expecting this level of austerity."
Technological innovation can be particularly appealing when the aim is to stretch resources while also improving care. Characteristically, David Oliver calls for caution in his perspective on telehealth (doi:10.1136/bmj.j5108). Anything that helps people stay at home, retain their independence, manage their health, or avoid admission to hospital is worth trying, he says. But new technologies should be tested to the same standards of evidence as other innovations, he says. Evidence of benefit is often limited, that of cost effectiveness even less so. In the absence of randomised controlled trials, he asks for large quality improvement studies, with independent scrutiny, release of all data, and, crucially, no commercial spin.

We need the same independent scientific approach to innovations in primary care, says Rebecca Rosen (doi:10.1136/ bmj.j5470). "GP at Hand" is the newest kid on the block, offering ready access to primary care through a smartphone. But will this merely fuel demand from the worried well? Worse, by cherry picking the young and healthy at the expense of most patients' more complex needs, will it fragment and undermine the NHS's famously cost effective primary care?

\section{Christmas appeal}

This week we launch our annual Christmas appeal, with Médecins Sans Frontières this year's charity (doi:10.1136/bmj. j5535). MSF provides independent humanitarian support in some of the world's most remote and dangerous locations. With your help it can continue and extend its vital work. 